\title{
A rare case of massive hepatosplenomegaly due to acute lymphoblastic leukaemia in pregnancy
}

\author{
R Gonçalves, MB ChB, MMed (Int Med), Cert Cardiol; R Meel, MB ChB, MMed (Int Med), Cert Cardiol, PhD \\ Department of Internal Medicine, School of Medicine, Faculty of Health Sciences, University of Pretoria and Steve Biko Academic Hospital, \\ Pretoria, South Africa
}

Corresponding author: $R$ Gonçalves (drrgoncalves@gmail.com)

\begin{abstract}
Acute lymphoblastic leukaemia (ALL) is rarely seen in pregnancy. Massive hepatosplenomegaly as a presentation of ALL has not been described previously in any patient population. A 30-year-old pregnant woman presented at 16 weeks' gestation with epistaxis, jaundice, diffuse abdominal pain and distension, massive hepatosplenomegaly and peripheral oedema. On the basis of blood tests, bone marrow biopsy and imaging, a diagnosis of ALL complicated by massive hepatosplenomegaly with splenic infarctions was made. The patient was referred to oncology for appropriate chemotherapy.
\end{abstract}

S Afr Med J 2017;107(5):402-404. DOI:10.7196/SAMJ.2017.v107i5.12313

Cancer in pregnancy is rare, occurring in about one in 1000 pregnancies. ${ }^{[1]}$ The most common malignancies in pregnancy are breast cancer, cervical cancer, melanoma, leukaemia and lymphoma. Specifically, acute leukaemia is extremely uncommon in pregnancy, with an incidence of 1 in $75000 .^{[2]}$ Acute lymphoblastic leukaemia (ALL) accounts for $28 \%$ of cases of leukaemia diagnosed during pregnancy, the remainder being acute myeloid and chronic myeloid leukaemias. ${ }^{[3]}$ Massive hepatosplenomegaly as a presentation of ALL has not been reported previously in any patient population. We describe the first case of massive hepatosplenomegaly in a pregnant patient with ALL.

\section{Case report}

A 30-year-old pregnant woman, previously healthy, presented with a 3-week history of nosebleeds, yellow discolouration of the eyes and skin, diffuse abdominal pain and distension, and swelling of the legs. The pain was worst in the left hypochondrium and was dull and constant. The epistaxis had worsened, prompting her to seek help at the referring hospital. She reported dyspnoea at rest and paroxysmal nocturnal dyspnoea. The urine was dark and the stools were pale. Fever, night sweats and weight loss of $\sim 5 \mathrm{~kg}$ were also reported.

Clinical examination revealed marked pallor, without significant lymphadenopathy. Peripheral oedema and overt jaundice were noted. The urine was dark, with bilirubin present on dipstick examination. Her vital signs revealed a tachycardia (126 bpm), a blood pressure of $114 / 64 \mathrm{mmHg}$ and a respiratory rate of 36 breaths per minute. Cardiovascular examination was remarkable only for an ejection systolic murmur over the base of the heart. The findings on respiratory examination were normal. The abdomen was distended, with significant tenderness on light palpation. Rebound tenderness but no rigidity was present. There was clinical hepatosplenomegaly, with a liver span of $26 \mathrm{~cm}$ in the mid-clavicular line and the spleen measuring $14.5 \mathrm{~cm}$ inferior to the lower rib margin. The uterus was palpable (about 16 - 18 weeks' gestation). Signs of ascites could not be elicited owing to the tenderness. Examination of the head and neck revealed no epistaxis at the time of examination, and no obvious nasal pathology. The findings on skin and musculoskeletal examination were normal.
A full blood count revealed anaemia (red blood cell count $4.62 \times 10^{12} / \mathrm{L}$, haemoglobin $10.6 \mathrm{~g} / \mathrm{dL}$, haematocrit 0.324 , mean corpuscular volume $70 \mathrm{fL}$, mean corpuscular haemoglobin $23 \mathrm{pg}$, mean corpuscular haemoglobin concentration $32.8 \mathrm{~g} / \mathrm{dL}$ ), with a platelet count of $525 \times 10^{\%} / \mathrm{L}$ and a white cell count of $10.5 \times 10^{9} / \mathrm{L}$. Leukaemic blasts were noted in the blood. Serum biochemical investigations showed normal renal function and features consistent with cholestasis on liver enzyme tests. The erythrocyte sedimentation rate and C-reactive protein level were elevated at $78 \mathrm{~mm} / \mathrm{h}$ and $86.1 \mathrm{mg} / \mathrm{L}$, respectively.

A chest radiograph and abdominal ultrasound scan were requested. An elevated diaphragm was noted on the chest radiograph (Fig. 1). An abdominal ultrasound scan revealed no thrombi in the inferior vena cava or the portal or iliac veins. The liver was enlarged $(25 \mathrm{~cm}$ in the mid-clavicular line) with normal portal vein and hepatic vein flow. The gallbladder wall was thickened. The kidneys were normal in size. The spleen was enlarged at $19 \times$ $9 \mathrm{~cm}$. Ascites was present. A fetus was noted, about 16 weeks' gestational age, with a heart rate of $145 \mathrm{bpm}$. Despite the pregnancy, we elected to perform a computed tomography (CT) scan of the chest to exclude a pulmonary embolism. No pulmonary embolism was evident, and no lymphadenopathy was noted in the chest. The scan was extended to the abdomen to identify the cause of the abdominal pain and delineate the pathology better. It showed massive hepatosplenomegaly with multiple splenic infarctions (Fig. 2). There was compression of the inferior vena cava (IVC) and features of portal hypertension. No abdominal lymphadenopathy was present.

A bone marrow aspirate was consistent with acute leukaemia, with $23 \%$ blast cells. In conjunction with the flow cytometry, the overall picture was suggestive of precursor T-cell ALL with aberrant expression of CD16.

A final diagnosis of precursor T-cell ALL in a pregnant patient, complicated by massive hepatosplenomegaly with multiple splenic infarctions, cholestasis and probable portal hypertension, was made. The patient was referred to oncology, where she was treated with steroids and combination chemotherapy including anthracyclines. 


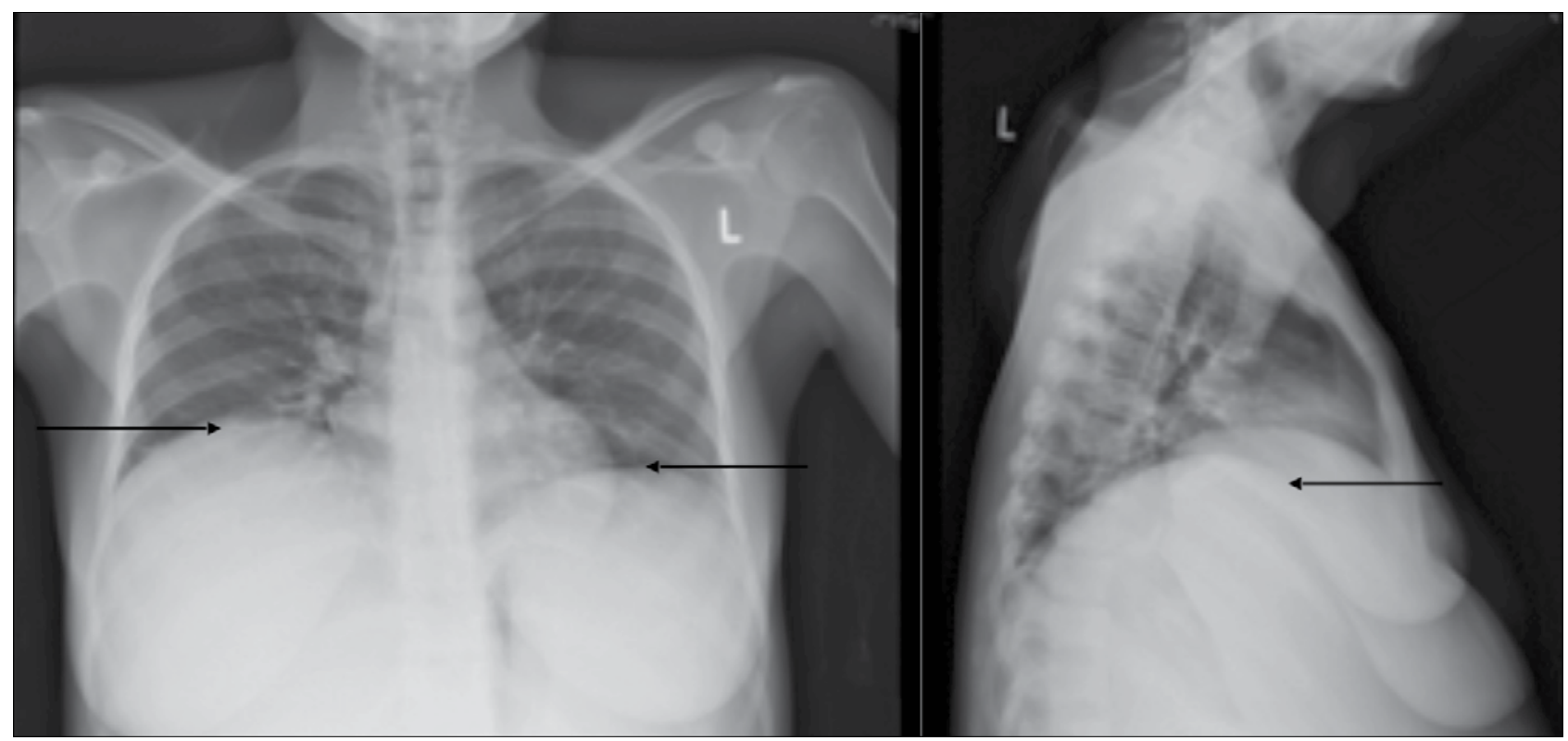

Fig. 1. Chest radiograph (anteroposterior (left) and lateral (right) views) demonstrating an elevated diaphragm (arrows) caused by massive hepatosplenomegaly.

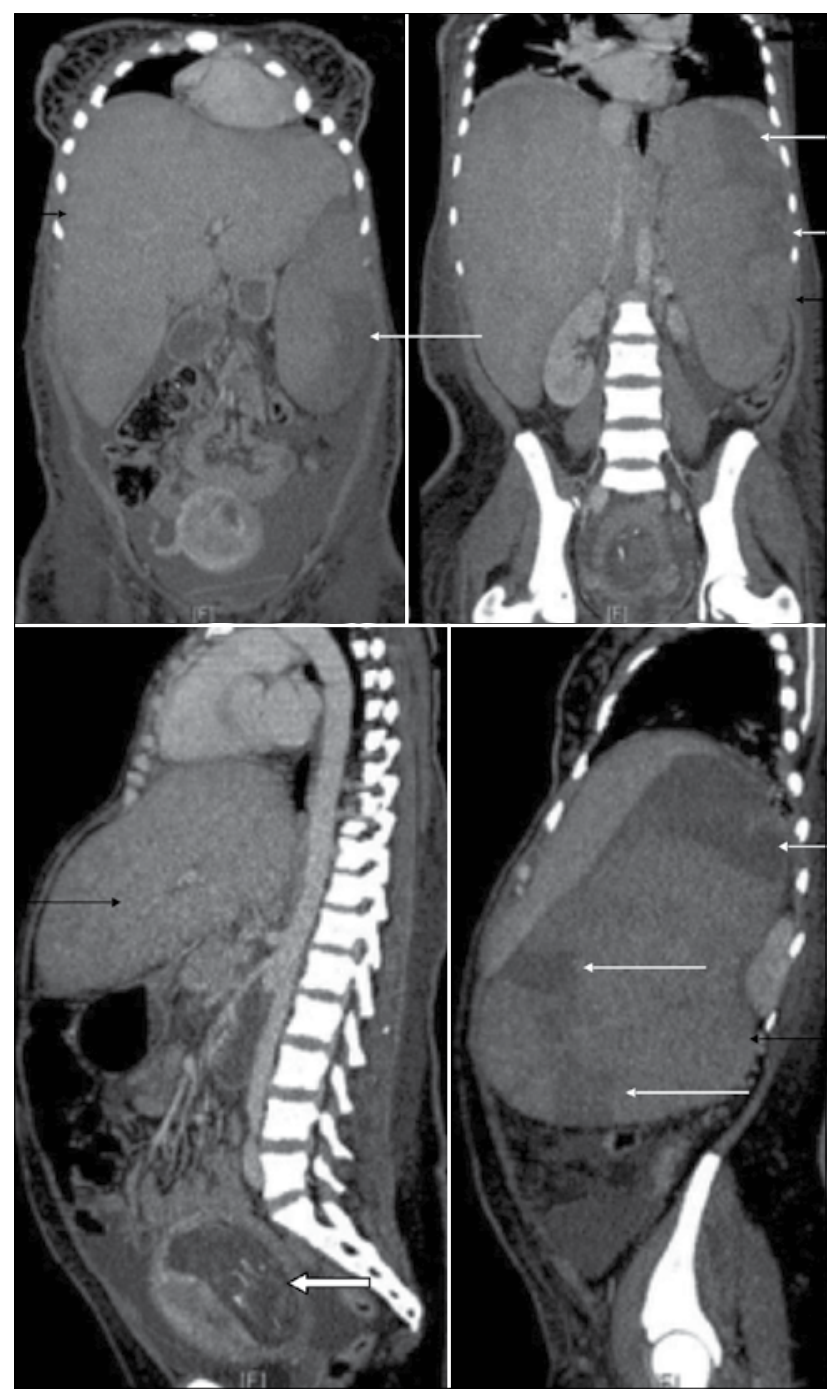

Fig. 2. CT scan of the abdomen (coronal (top) and sagittal (bottom) views) demonstrating massive hepatosplenomegaly (black arrows), splenic infarcts (white arrows) and a 16-week fetus (white block arrow).

\section{Discussion}

This case represents a rare presentation of an uncommon malignancy in pregnancy. Massive hepatosplenomegaly, although common in chronic myeloid leukaemias, has not been described as a presentation of ALL at all. The most common listed causes of massive hepatosplenomegaly include chronic lymphoproliferative malignancies, infections (malaria, leishmaniasis) and glycogen storage diseases (Gaucher's disease). ${ }^{[4]}$ In our case the probable causes of the massive hepatosplenomegaly were a combination of late presentation after symptom onset, leukaemic infiltration and secondary compression of the IVC with resultant portal hypertension.

The case highlights the importance of maintaining a high index of suspicion for uncommon causes of massive hepatosplenomegaly as well as rare malignancies in pregnancy. ALL is diagnosed occasionally in pregnancy. ${ }^{[5]}$ Early diagnosis and treatment are advisable. Pregnancy itself does not alter the course of acute leukaemia, but urgent chemotherapy is essential to improve the outcome. Treatment in the first trimester carries a high risk of fetal anomalies and miscarriage. Leukapheresis may be considered in the first trimester to delay chemotherapy.

In recent years, numerous reports have addressed issues pertaining to chemotherapy in later stages of pregnancy. ${ }^{[5-14]}$ Chemotherapy was well tolerated by the majority of patients, with a low incidence of spontaneous abortion. Germann et al. ${ }^{[5]}$ reported normal deliveries in $73 \%$ of 160 pregnant patients treated with anthracycline chemotherapy. Intensive chemotherapy in the second and third trimesters does not pose an inordinate risk to fetal or neonatal development, although increased rates of premature delivery and perinatal mortality, and lower birth weight for gestational age, have been noted. ${ }^{[5-14]}$

A multidisciplinary approach involving the patient, obstetrician, physician, haematologist and oncologist is mandatory for optimal clinical outcome.

Acknowledgements. Consent was obtained from the patient for publication of this case report.

Author contributions. The authors contributed in equal part to the preparation of this manuscript. 
Funding. None.

Conflicts of interest. None.

1. Donegan WL. Cancer and pregnancy. CA Cancer J Clin 1983:33(4):194-214

2. Lichtman MA, Liesveld JL. Acute myelogenous leukemia. In: Beutle RE, Lichtman MA, Coller BS, Kipps TJ, Seligsohn U, eds. Williams Hematology. 6th ed. New York: McGraw-Hill, 2001:10471084.

3. Terek M, Ozkinay E, Zekioglu O, et al. Acute leukemia in pregnancy with ovarian metastasis: A case report and review of the literature. Int J Gynecol Cancer 2003;13(6):904-908.

4. Houghton AR, Gray D. The gastrointestinal system. In: Houghton AR, Gray D, eds. Chamberlain's Symptoms and Signs in Clinical Medicine: An Introduction to Medical Diagnosis. 13th ed. London: Hodder Arnold, 2010:108-136.

5. Germann N, Goffinet F, Goldwasser F. Anthracyclines during pregnancy: Embryo-fetal outcome in 160 patients. Ann Oncol 2004;15(1):146. http://dx.doi.org/10.1093/annonc/mdh009

6. Saleh AJ, Alhejazi A, Ahmed SO, et al. Leukemia during pregnancy: Long term follow up of 32 cases from a single institution. Hematol Oncol Stem Cell Ther 2014;7(2):63-68. http://dx.doi.org/10.1016/j. hemonc.2014.03.001

7. Chelghoum Y, Vey N, Raffoux E, et al. Acute leukemia during pregnancy: A report on 37 patients and a review of the literature. Cancer 2005;104(1):110-117. http://dx.doi.org/10.1002/cncr.21137
8. Molkenboer JF, Vos AH, Schouten HC, et al. Acute lymphoblastic leukaemia in pregnancy. Neth J Med 2005;63(9):361-363

9. Pizzuto J, Aviles A, Noriega L, et al. Treatment of acute leukemia during pregnancy: Presentation of nine cases. Cancer Treat Rep 1980;64(4-5):679-683.

10. Ticku J, Oberoi S, Friend S, et al. Acute lymphoblastic leukemia in pregnancy: A case report with literature review. Ther Adv Hematol 2013;4(5):313-319. http://dx.doi.org/10.1177/204062071349293 1. Reynoso EE, Shepherd FA, Messner HA, et al. Acute leukemia during pregnancy: The Toronto Leukemia Study Group experience with long-term follow-up of children exposed in utero to chemotherapeutic agents. J Clin Oncol 1987;5(7):1098-1106.

12. CardonickE, Iacobucci A. Use of chemotherapy during human pregnancy. Lancet Oncol 2004;5(5):283291. http://dx.doi.org/10.1016/S1470-2045(04)01466-4

13. Khandaker S, Munshi S. A rare case of acute lymphoblastic leukaemia in pregnancy - unique maternal-fetal challenges. J Clin Diagn Res 2014;8(10):OD10-OD12. http://dxdoiorg/10.7860/ JCDR/2014/9720.5069

14. Milojkovic D, Apperley JF. How I treat leukemia during pregnancy. Blood 2014;123(7):974-984. http:// dx.doi.org/10.1182/blood-2013-08-283580

Accepted 18 January 2017. 